\title{
Use of mixed Li/K metal TMP amide (LiNK chemistry) for the synthesis of [2.2]metacyclophanes
}

\author{
Marco Blangetti, Patricia Fleming and Donal F. O'Shea*
}

\author{
Full Research Paper \\ Address: \\ Centre for Synthesis and Chemical Biology, School of Chemistry and \\ Chemical Biology, University College Dublin, Belfield, Dublin 4, \\ Ireland \\ Email: \\ Donal F. O'Shea* - donal.f.oshea@ucd.ie \\ * Corresponding author \\ Keywords: \\ benzylic metalation; LiNK chemistry; [2.2]metacyclophane; oxidative \\ coupling; planar chirality
}

Beilstein J. Org. Chem. 2011, 7, 1249-1254.

doi:10.3762/bjoc. 7.145

Received: 16 May 2011

Accepted: 21 July 2011

Published: 09 September 2011

This article is part of the Thematic Series "Directed aromatic functionalization".

Guest Editor: V. Snieckus

(C) 2011 Blangetti et al; licensee Beilstein-Institut.

License and terms: see end of document.

\begin{abstract}
A new two-step general approach to [2.2] metacyclophane synthesis from substituted $m$-xylenes is described. The strategy employs a selective benzylic metalation and oxidative $\mathrm{C}-\mathrm{C}$ bond formation for both synthetic operations. Regioselective benzylic metalation is achieved using the $\mathrm{BuLi}, \mathrm{KO}$ - $\mathrm{Bu}, \mathrm{TMP}(\mathrm{H})(2,2,6,6$-tetramethylpiperidine) combination (LiNK metalation conditions) and oxidative coupling with 1,2-dibromoethane. The synthetic ease of this approach compares favourably with previously reported methods and allows for ready access to potentially useful planar chiral derivatives.
\end{abstract}

\section{Introduction}

While direct metalation reactions are an essential contribution to the repertoire of modern synthetic methods, an underlying and often underestimated challenge remains in the achievement of predictable selective metalations of substrates that offer several potential sites of reaction. Examples of such challenges include the selective aryl metalation of arenes containing more than one directing group (DG), arene metalation in positions not ortho to the directing group, or the identification of reaction conditions to achieve selective benzylic metalation of substituted toluenes 1 to provide 3 (Scheme 1) [1-5]. We recently reported that mixed $\mathrm{Li} / \mathrm{K}$ metal TMP amide (LiNK metalation conditions) is uniquely suited for the selective achievement of challenging metalations. Specifically, the use of the reagent triad $\mathrm{BuLi} / \mathrm{KO} t-\mathrm{Bu} / \mathrm{TMP}(\mathrm{H})$ to generate a mixed $\mathrm{Li} / \mathrm{K}$ metal TMP amide in situ has proven to be an efficient and general method to achieve vinyl and benzylic metalations with excellent selectivity [6,7]. We now exploit this selective benzylic metalation protocol for the specific synthesis of [2.2]metacyclophanes.

Chemists have a long-standing fascination for the [2.2]cyclophane structures and have extensively studied their unusual 


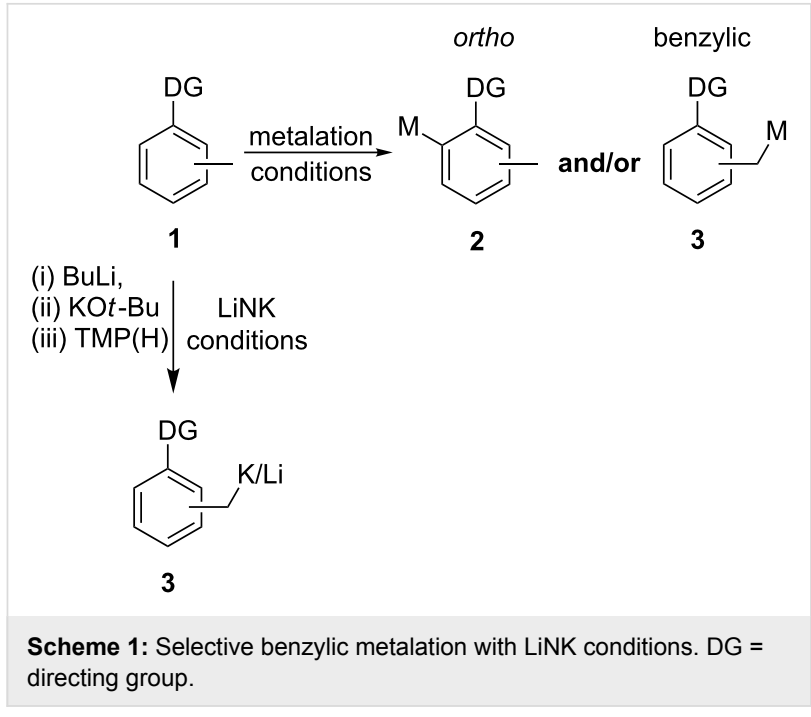

physical and chemical properties induced by the close spatial proximity of their aryl rings [8]. Undoubtedly the most studied of the series (ortho, meta and para) are the [2.2]paracyclophanes, which have seen a recent resurgence of interest notably as planar chiral scaffolds for asymmetric catalysis [9-13] Surprisingly, the [2.2]metacyclophanes, which also have the potential to be exploited as planar chiral templates, have received scant attention since the seminal reports of Schlögl in the early 1970s [14-16]. One possible explanation for this is the cumbersome methods required for their synthesis. Typical approaches have utilised Wurtz coupling, the oxidation and thermal $\left(500-600{ }^{\circ} \mathrm{C}\right)$ extrusion of $\mathrm{SO}_{2}$ from dithia[3.3]cyclophanes or the photochemical ring contraction of diselena[3.3]cyclophanes [17-21].

We envisaged that our LiNK metalation conditions with in situ oxidative coupling could offer a facile general approach to [2.2]metacyclophanes, which would be of general synthetic interest (Scheme 2). Oxidative homo-coupling of benzyl anions has previously been noted, but it has remained relatively unexplored as a synthetic procedure [22-24]. We speculated that if oxidative coupling of the benzyl metalated xylenes 5 could be achieved to form the open dimer $\mathbf{6}$, then a second metalation and oxidative ring closure would yield the [2.2] metacyclophanes 8. A stepwise approach, as shown in Scheme 2, could allow for the introduction of different groups on each of the aryl rings. In addition, it could facilitate the synthesis of planar chiral derivatives without the complication of mixtures with achiral isomers being generated, which occurs if, for example, a 1-substituted-2,4-bis(halomethyl)benzene is used as the starting compound [15].

\section{Results and Discussion}

In order to examine the scope and potential of this approach, five differently substituted xylenes were investigated, namely $m$-xylene (4a), mesitylene (4b), 1-methoxy-3,5-dimethylbenzene (4c), (3,5-dimethylphenyl)dimethylamine (4d) and 2,4dimethylbenzoic acid (4e) (Figure 1). These xylenes present interesting challenges for metalation selectivity in that for derivatives $\mathbf{4 a - d}$ both methyl groups are equivalent and so the

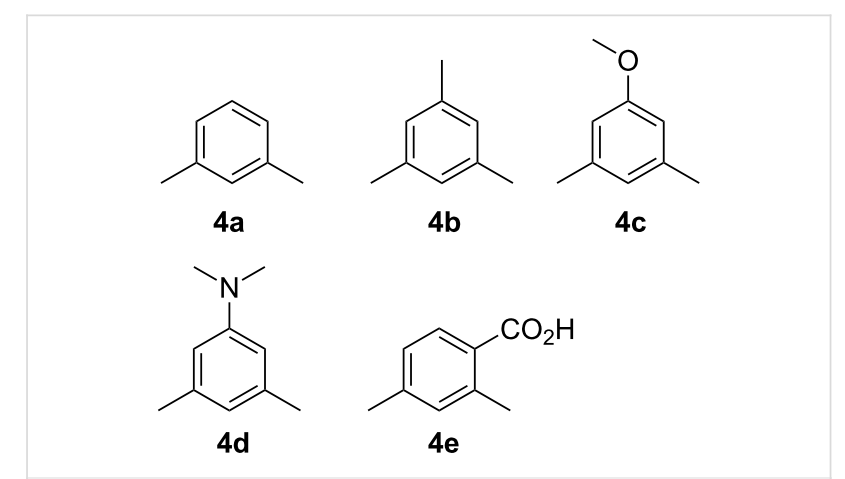

Figure 1: Xylene substrates.

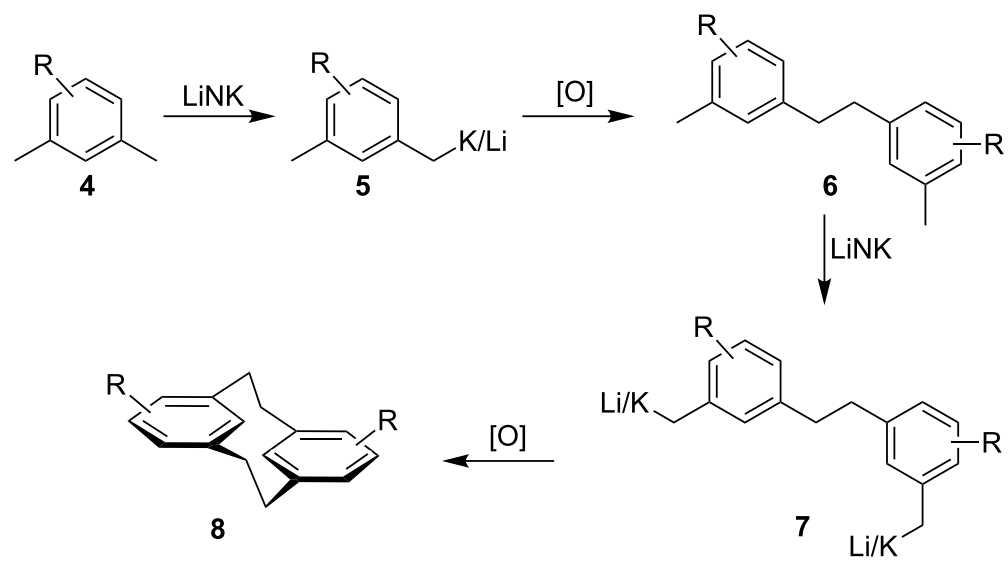


alternative metalation sites are in the aryl ring, whereas the challenge is elevated for $\mathbf{4 e}$ as it contains two differing benzylic sites and an ortho-aryl position primed for metalation by a strong directing group.

Sequential treatment of $\mathbf{4 a - d}$ with $\mathrm{BuLi}, \mathrm{KO} t-\mathrm{Bu}$ and $\mathrm{TMP}(\mathrm{H})$ at $-78{ }^{\circ} \mathrm{C}$ followed by the oxidant 1,2-dibromoethane [25] gave good to excellent yields of the targeted homo-dimer products 6a-d (Table 1, entries 1-4). It was also possible to form a "mixed dimer" by the reaction of $\mathbf{4 a}$ and $\mathbf{4} \mathbf{c}$ together, which gave 6e, containing one $m-\mathrm{OCH}_{3}$ substituted aryl ring, in a $22 \%$ yield (Table 1, entry 5) following chromatography to remove the other homo-coupled products $(\mathbf{6 a}, \mathbf{6 c})$. A similar approach was used in a combined reaction of $\mathbf{4 a}$ and $\mathbf{4 e}$, giving purified 4-methyl-2-(3-methylphenethyl)benzoic acid (6f) (Table 1, entry 6$)$. This product is the result of oxidative hetero coupling of benzylic metalated xylene and 2-(methyl-metalated)-4methylbenzoate.

To more clearly illustrate a site selective metalation of $4 \mathbf{e}$ for the methyl group ortho to the carboxylate, this substrate was metalated using LiNK metalation conditions (using an addition equivalent of BuLi to first deprotonate the carboxylic acid) and quenched with $\mathrm{CD}_{3} \mathrm{OD}$. It was anticipated that under our low temperature yet thermodynamically controlled conditions the selective site of metalation should be the more acidic 2-methyl position [26]. This was confirmed by ${ }^{2} \mathrm{H}$ NMR, which showed that incorporated deuterium was above $90 \%$ in the 2 -methyl position with less than $10 \%$ in the 4-methyl group and no detectable aryl deuteration (Figure 2).

A similar experiment was carried out for the even more complex hetero-dimer substrate $\mathbf{6 f}$, in which a selective di-benzylic metalation of the two different methyl positions was attempted. Treatment of $\mathbf{6} \mathbf{f}$ with three equivalents of BuLi (one to deprotonate the carboxylic acid) and two equivalents of $\mathrm{KO} t-\mathrm{Bu} /$ TMP $(H)$ followed by deuteration gave the di-deuterated product $\mathrm{D}_{2}$-6f. ${ }^{2} \mathrm{H}$ NMR analysis showed no aryl or bridging methylene deuteration, with deuterium incorporated only into the two non-equivalent benzylic methyl positions (Figure 3 ).

With the benzylic metalation confirmed, the second step to complete the [2.2]metacyclophane synthesis required identical conditions to the first to provide the di-benzylic metalated derivatives 7 (Table 2). We anticipated that an intramolecular ring closing by oxidative coupling would provide the desired

Table 1: Oxidative coupling of benzylic metalated xylenes 4

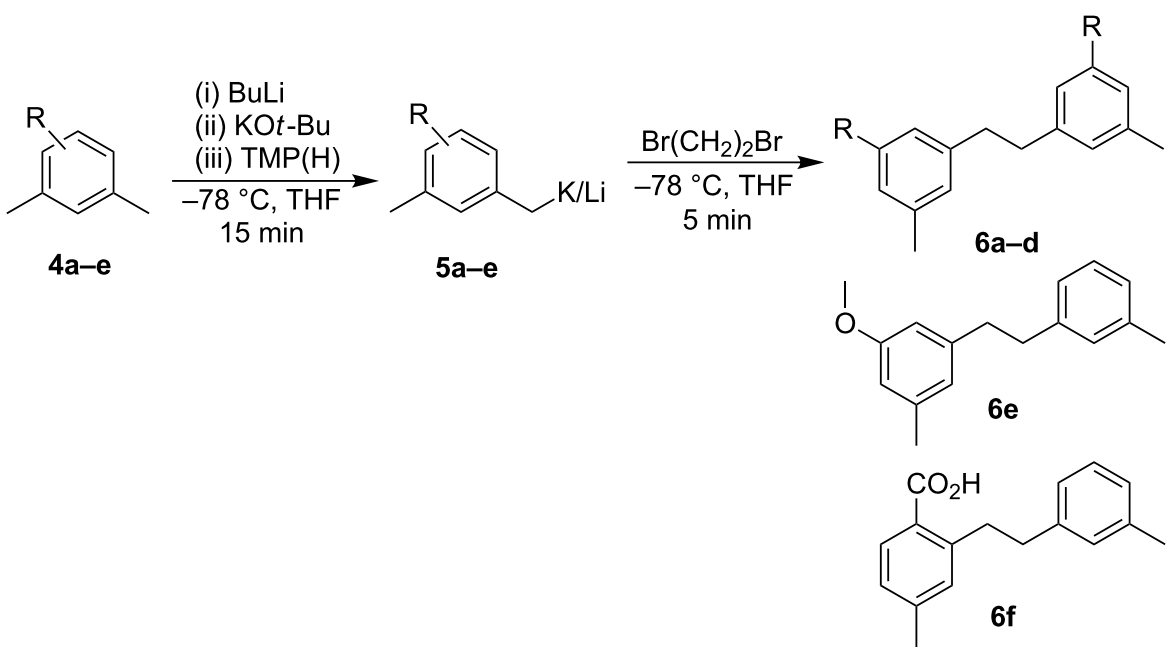

\begin{tabular}{lllll}
\hline Entry & Substrate & $\mathrm{R}$ & Product \\
\hline 1 & $\mathbf{4 a}$ & $\mathrm{H}$ & $\mathbf{6 a}$ & 91 \\
2 & $\mathbf{4 b}$ & $\mathrm{CH}_{3}$ & $\mathbf{6 b}$ & 72 \\
3 & $\mathbf{4 c}$ & $\mathrm{OCH}_{3}$ & $\mathbf{6 c}$ & 92 \\
4 & $\mathbf{4 d}$ & $\mathrm{N}\left(\mathrm{CH}_{3}\right)_{2}$ & $\mathbf{6 d}$ & $\mathbf{6 e}$ \\
5 & $\mathbf{4 a / 4 c}$ & $\mathrm{OCH}_{3} / \mathrm{H}$ & $\mathbf{6 e}$ & $12^{\mathrm{a}}$ \\
6 & $\mathbf{4 a / 4 e}$ & $\mathrm{CO}_{2} \mathrm{H} / \mathrm{H}$ & $\mathbf{6 f}$ & \\
\hline
\end{tabular}

a 6 a and $\mathbf{6 c}$ also obtained in $14 \%$ and $49 \%$ yields respectively.

${ }^{\mathrm{b}} 6 \mathrm{a}$ and dimer of $4 \mathrm{e}$ also obtained in $11 \%$ and $62 \%$ yields respectively. 


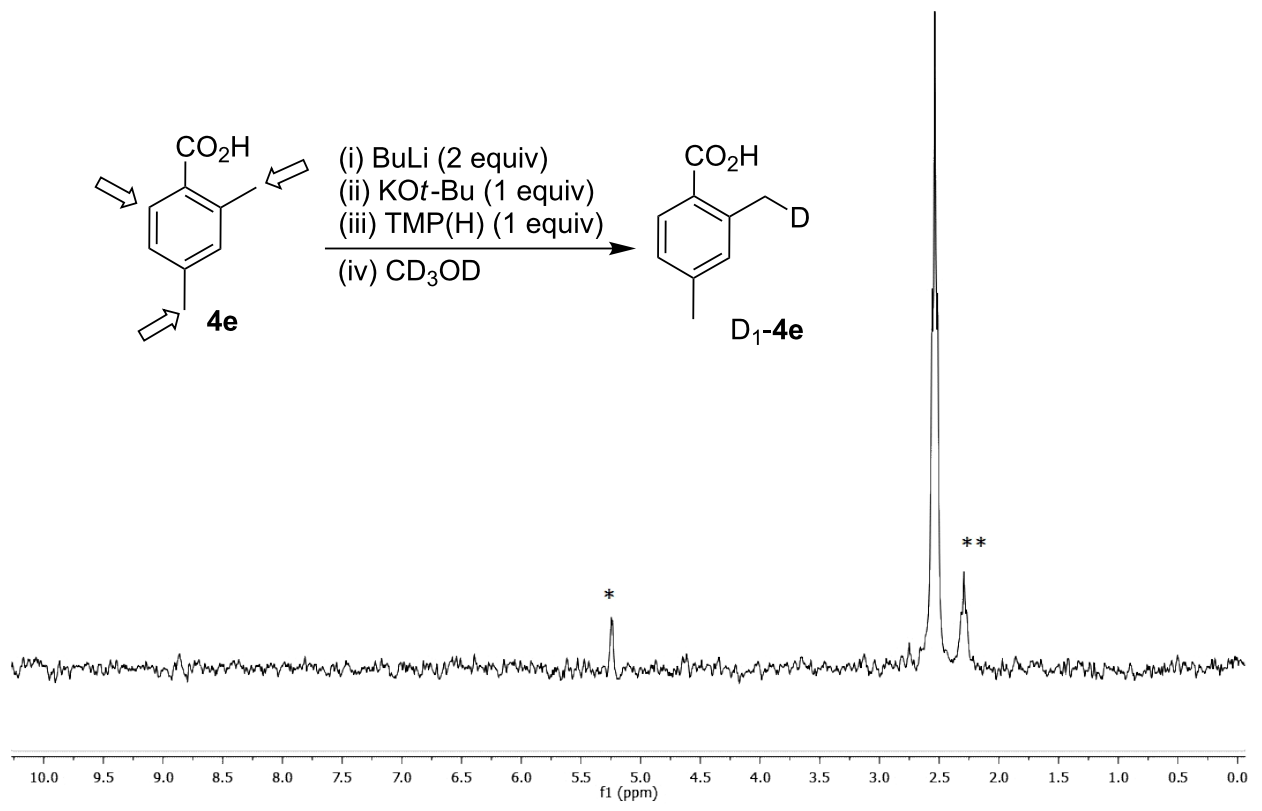

Figure 2: Metalation selectivity for $4 \mathrm{e}$ (arrows indicate potential metalation sites). ${ }^{2} \mathrm{H}$ NMR spectrum in $\mathrm{CH}_{2} \mathrm{Cl}_{2} .{ }^{*} \mathrm{CD}_{2} \mathrm{Cl}_{2}$. ${ }^{* *} 2-\mathrm{Methyl} 4-\mathrm{D}-\mathrm{methylben}-$ zoic acid.

cyclophane product in addition to open chain oligomers or larger ring systems.

Substrates $\mathbf{6 a}-\mathbf{e}$ were treated with two equivalents of $\mathrm{BuLi} /$ $\mathrm{KO} t-\mathrm{Bu} / \mathrm{TMP}(\mathrm{H})$ to generate the corresponding dianions $\mathbf{7 a}-\mathbf{e}$, which upon oxidative coupling gave the corresponding metacyclophanes 8a-e. This provided unsubstituted cyclophane 8a in $40 \%$ yield and 5,13-disubstituted derivatives $8 \mathbf{b}-\mathbf{d}$, containing $\mathrm{CH}_{3}, \mathrm{OCH}_{3}$ and $\mathrm{N}\left(\mathrm{CH}_{3}\right)_{2}$ substituents respectively, in comparable yields (Table 2, entries $1-4$ ). In addition, the mono-

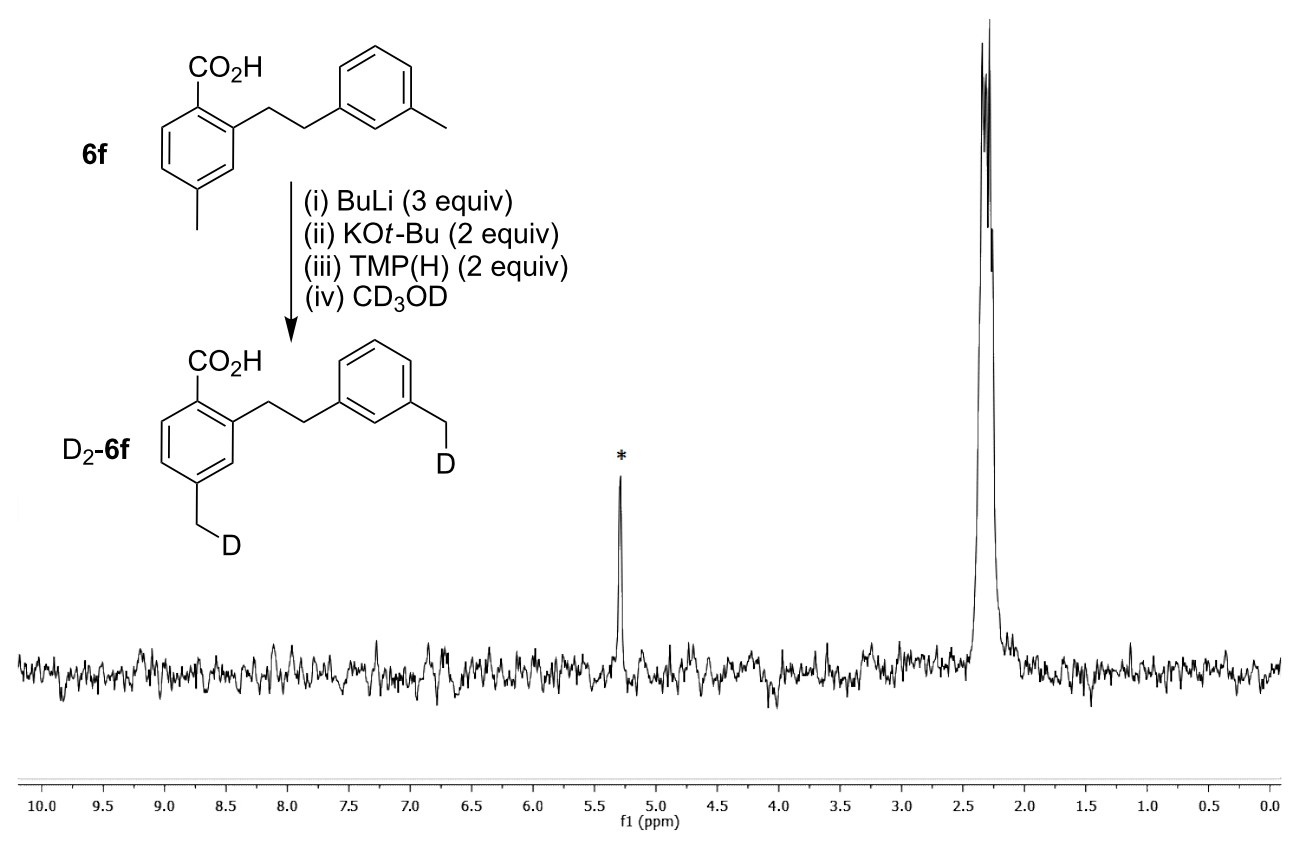

Figure 3: Di-metalation selectivity for 6 f. ${ }^{2} \mathrm{H}$ NMR spectrum in $\mathrm{CH}_{2} \mathrm{Cl}_{2} \cdot{ }^{*} \mathrm{CD}_{2} \mathrm{Cl}_{2}$. 
Table 2: Metalation/oxidative coupling to [2.2]metacyclophanes.<smiles>[R][X]1ccc(CCc2ccc(C)c(C)c2)cc1</smiles>

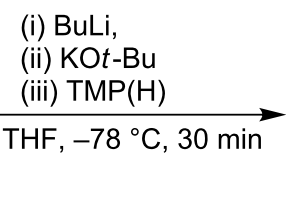

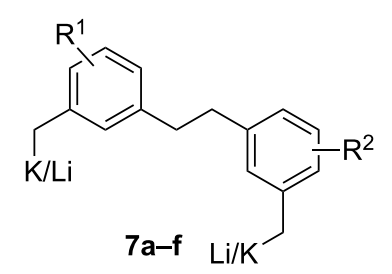

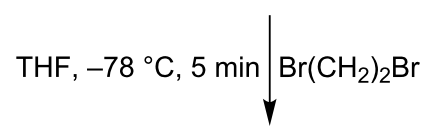

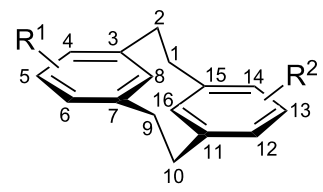

8a-f

\begin{tabular}{llllll}
\hline Entry & Substrate & $\mathrm{R}^{1} / \mathrm{R}^{2}$ & Position & Product & Yield \% \\
\hline 1 & $\mathbf{6 a}$ & $\mathrm{H} / \mathrm{H}$ & - & $\mathbf{8 a}$ & 40 \\
2 & $\mathbf{6 b}$ & $\mathrm{CH}_{3} / \mathrm{CH}_{3}$ & 5,13 & $\mathbf{8 b}$ & 54 \\
3 & $\mathbf{6 c}$ & $\mathrm{OCH}_{3} / \mathrm{OCH}_{3}$ & 5,13 & $\mathbf{8 c}$ & 33 \\
4 & $\mathbf{6 d}$ & $\mathrm{N}\left(\mathrm{CH}_{3}\right)_{2} / \mathrm{N}^{2}\left(\mathrm{CH}_{3}\right)_{2}$ & 5,13 & $\mathbf{8 d}$ & 43 \\
5 & $\mathbf{6 e}$ & $\mathrm{OCH}_{3} / \mathrm{H}$ & 5 & $\mathbf{8 e}$ & 42 \\
6 & $\mathbf{6 f}$ & $\mathrm{CO}_{2} \mathrm{H} / \mathrm{H}$ & 4 & $\mathbf{8 f}$ & 39
\end{tabular}

methoxy substituted derivative 6e was effectively ring closed under our reaction conditions to yield $\mathbf{8 e}$ in a $42 \%$ yield. In each case, the majority of the remaining material was oligomeric in nature, although it was not characterised. Substrate $\mathbf{6 f}$ offered the potential to generate the planar chiral 4-carboxylic acid substituted metacyclophane $\mathbf{8 f}$. This was readily achieved in a $39 \%$ yield, with the characteristic NMR aromatic proton signals for $\mathrm{C}(\mathrm{H})-8 / 16$ observed at 4.21 and $4.18 \mathrm{ppm}$. The efficient two step synthesis of a C(4)-substituted planar chiral 8f was achieved from inexpensive substrates, under identical reagent conditions for both steps. This compares favourably to the previously reported elaborate seven step synthesis, which was required due to the difficulties of incorporating substituents at the $\mathrm{C}(4)$ position after metacyclophane synthesis [27,28]. The resolution of $\mathbf{8 f}$ by salt formation with (+)-1-phenylethylamine [27] has previously been accomplished.

The stepwise anti conformation of the metacyclophane $8 \mathbf{c}$ was confirmed by single crystal X-ray analysis. Cyclophane 8c crystallised by the slow room temperature evaporation of a diethyl ether solution, into the monoclinic space group $P 2_{1} / n$ as shown in Figure 4. 8c contains an inversion centre with the co-planar aromatic rings bent into shallow boat forms with an angle of $8.9(1)^{\circ}$ from planarity. The intra-annular distance as measured from $C(8)$ to $C(16)$ is as expected for [2.2]metacyclophanes at 2.66(1) $\AA[29]$.

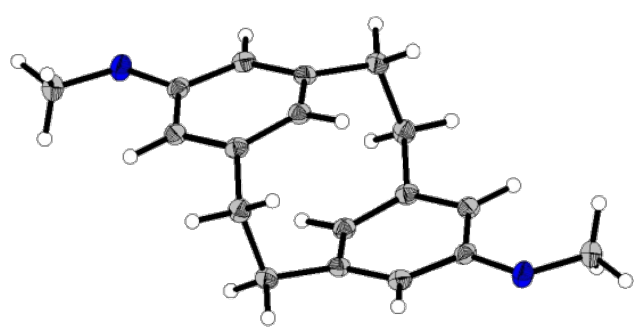

Figure 4: X-Ray structure of $8 \mathrm{c}$ with thermal ellipsoids drawn at $50 \%$ probability level.

\section{Conclusion}

A new two-step general approach to [2.2]metacyclophane synthesis was described from substituted $m$-xylenes. Our strategy employs a selective benzylic metalation and oxidative $\mathrm{C}-\mathrm{C}$ bond formation for both synthetic operations under LiNK metalation conditions. The synthetic ease of this approach compares 
favourably with previously reported methods and allows for ready access to potentially useful planar chiral derivatives. Expansion of this strategy to other chiral cyclophane architectures is ongoing and will be reported in due course. Additional synthetic applications of LiNK metalation conditions are also under development.

\section{Supporting Information}

\section{Supporting Information File 1}

All experimental details, ${ }^{1} \mathrm{H}$ and ${ }^{13} \mathrm{C}$ NMR spectra for compounds 6a-f and 8a-f and X-ray crystallographic data for $8 \mathbf{c}$.

[http://www.beilstein-journals.org/bjoc/content/ supplementary/1860-5397-7-145-S1.pdf]

\section{Acknowledgements}

We thank the Science Foundation Ireland, The Irish Research Council for Science, Engineering and Technology and ERAChemistry for financial support. Thanks to Dr. J. Muldoon for NMR analysis and Dr. Helge Müller-Bunz for X-ray structure.

\section{References}

1. Whisler, M. C.; MacNeil, S.; Snieckus, V.; Beak, P. Angew. Chem., Int. Ed. 2004, 43, 2206-2225. doi:10.1002/anie. 200300590

2. Schlosser, M. Angew. Chem., Int. Ed. 2005, 44, 376-393. doi:10.1002/anie.200300645

3. Mulvey, R. E. Acc. Chem. Res. 2009, 42, 743-755. doi:10.1021/ar800254y

4. Clark, R. D.; Jahangir, A. Org. React. 1995, 47, 1-314 doi:10.1002/0471264180.or047.01

5. Clayden, J. Regioselective Synthesis of Organolithiums by Deprotonation. In Organolithiums: Selectivity for Synthesis; Baldwin, J. E.; Williams, R. M., Eds.; Pergamon Press: Oxford, U.K., 2002; pp 9-110.

6. Tricotet, T.; Fleming, P.; Cotter, J.; Hogan, A.-M. L.; Strohmann, C.; Gessner, V. H.; O'Shea, D. F. J. Am. Chem. Soc. 2009, 131 3142-3143. doi:10.1021/ja809941n

7. Fleming, P.; O'Shea, D. F. J. Am. Chem. Soc. 2011, 133, 1698-1701. doi:10.1021/ja110234v

8. Cram, D. J.; Cram, J. M. Acc. Chem. Res. 1971, 4, 204-213. doi:10.1021/ar50042a003

9. Liu, X.; Ma, Y.; Duan, W.; He, F.; Zhao, L.; Song, C. J. Org. Chem. 2011, 76, 1953-1956. doi:10.1021/jo102538y

10. Aly, A. A.; Brown, A. B. Tetrahedron 2009, 65, 8055-8089. doi:10.1016/j.tet.2009.06.034

11. Vorontsova, N. V.; Rozenberg, V. I.; Sergeeva, E. V.; Vorontsov, E. V.; Starikova, Z. A.; Lyssenko, K. A.; Hopf, H. Chem.-Eur. J. 2008, 14 4600-4617. doi:10.1002/chem.200701683

12. Whelligan, D. K.; Bolm, C. J. Org. Chem. 2006, 71, 4609-4618. doi:10.1021/jo060668h

13. Gibson, S. E.; Knight, J. D. Org. Biomol. Chem. 2003, 1, 1256-1269. doi:10.1039/b300717k
14. Glotzmann, C.; Langer, E.; Lehner, H.; Schlögl, K. Monatsh. Chem. 1975, 106, 763-777. doi:10.1007/BF00902182

15. Glotzmann, C.; Langer, E.; Lehner, H.; Schlögl, K. Tetrahedron Lett. 1975, 9, 675-678. doi:10.1016/S0040-4039(00)71952-6

16. Schlögl, K. Top. Curr. Chem. 1984, 125, 27-62.

17. Allinger, N. L.; Da Rooge, M. A.; Hermann, R. B. J. Am. Chem. Soc. 1961, 83, 1974-1978. doi:10.1021/ja01469a046

18. Akabori, S.; Sato, T.; Hata, K. J. Org. Chem. 1968, 33, 3277-3283. doi:10.1021/jo01272a051

19. Higuchi, H.; Tani, K.; Otsubo, T.; Sakata, Y.; Misumi, S. Bull. Chem. Soc. Jpn. 1987, 60, 4027-4036. doi:10.1246/bcsj.60.4027

20. Bodwell, G. J.; Houghton, T. J.; Kennedy, J. W. J.; Mannion, M. R. Angew. Chem., Int. Ed. Engl. 1996, 35, 2121-2123. doi:10.1002/anie.199621211

21. Vögtle, F.; Neumann, P. Synthesis 1973, 85-103. doi:10.1055/s-1973-22137

22. Bates, R. B.; Ogle, C. A. J. Org. Chem. 1982, 47, 3949-3952. doi:10.1021/jo00141a027

23. MacNeil, S. L.; Familoni, O. B.; Snieckus, V. J. Org. Chem. 2001, 66, 3662-3670. doi:10.1021/jo001402s

24. Nagano, T.; Hayashi, T. Chem. Lett. 2005, 34, 1152-1153. For the oxidative homo-coupling of Grignard reagents.

25. Aluri, B. R. Synlett 2008, 1579-1580. doi:10.1055/s-2008-1072785

26. Creger, P. L. J. Am. Chem. Soc. 1970, 92, 1396-1397. doi:10.1021/ja00708a048

27. Kainradl, B.; Langer, E.; Lehner, H.; Schlögl, K. Liebigs Ann. Chem. 1973, 766, 16-31. doi:10.1002/jlac.19727660104

28. Eberhardt, R.; Glotzmann, C.; Lehner, H.; Schlögl, K. Tetrahedron Lett. 1974, 15, 4365-4638. doi:10.1016/S0040-4039(01)92165-3

29. Crystal structure data deposited at the Cambridge Crystallographic Data Centre with deposit number CCDC 825095

\section{License and Terms}

This is an Open Access article under the terms of the Creative Commons Attribution License (http://creativecommons.org/licenses/by/2.0), which permits unrestricted use, distribution, and reproduction in any medium, provided the original work is properly cited.

The license is subject to the Beilstein Journal of Organic Chemistry terms and conditions: (http://www.beilstein-journals.org/bjoc)

The definitive version of this article is the electronic one which can be found at: doi:10.3762/bjoc. 7.145 